\title{
Hippocampal volume in early onset depression
} Frank P MacMaster*1,2 and Vivek Kusumakar ${ }^{3}$

\author{
Address: ${ }^{1}$ Institute for Biodiagnostics (Atlantic), National Research Council, Halifax, Canada, ${ }^{2}$ Department of Anatomy \& Neurobiology, \\ Dalhousie University, Halifax, Canada and ${ }^{3}$ Department of Psychiatry, Dalhousie University, Halifax, Canada \\ Email: Frank P MacMaster* - fpmacmas@dal.ca; Vivek Kusumakar - Vivek.Kusumakar@dal.ca \\ * Corresponding author
}

Published: 29 January 2004

BMC Medicine 2004, 2:2

This article is available from: http://www.biomedcentral.com/174I-7015/2/2

(C) 2004 MacMaster and Kusumakar; licensee BioMed Central Ltd. This is an Open Access article: verbatim copying and redistribution of this article are permitted in all media for any purpose, provided this notice is preserved along with the article's original URL.
Received: 26 September 2003

Accepted: 29 January 2004

\begin{abstract}
Background: Abnormalities in limbic structures have been implicated in major depressive disorder (MDD). Although MDD is as common in adolescence as in adulthood, few studies have examined youth near illness onset in order to determine the possible influence of atypical development on the pathophysiology of this disorder.
\end{abstract}

Methods: Hippocampal volumes were measured in 17 MDD subjects (age $=16.67 \pm 1.83$ years [mean \pm SD]; range $=13-18$ years $)$ and 17 age- and sex-matched healthy controls $(16.23 \pm 1.61$ years [mean $\pm \mathrm{SD}$ ]; 13 - 18 years) using magnetic resonance imaging (MRI).

Results: An analysis of covariance revealed a significant difference between MDD and control subjects $(F=8.66, d f=I, 29, P=0.006)$. This was more strongly localized to the left hippocampus $(P=0.00 \mathrm{I})$ than the right hippocampus $(P=0.047)$.

Conclusions: Our findings provide new evidence of abnormalities in the hippocampus in early onset depression. However, our results should be considered preliminary given the small sample size studied.

\section{Background}

Major depressive disorder (MDD) is a severe, common and debilitating illness with alarming rates of morbidity and mortality. Evidence suggests that child and adolescent MDD is continuous with adult MDD [1]. The lifetime prevalence of MDD in youth is approximately $15-20 \%$, which is consistent with adult rates of MDD [1].

Structural neuroimaging studies in adult MDD have explored the role of prefrontal cortex, basal ganglia and temporal limbic circuitry in the pathophysiology of the disorder [2]. In the hippocampus, studies of adult MDD have yielded mixed results, with some studies noting smaller volumes [3-11] while five studies failed to note significant differences in hippocampal volumes in adults with depression [12-16]. As noted by Sheline [17], the majority of the studies that reported negative results utilized a lower level of magnetic resonance imaging (MRI) resolution than the studies that had positive findings, and this difference in acquisition may have contributed to the divergent findings.

Few studies have examined brain structure in youth with MDD using MRI techniques [18]. Here, we examined hippocampal volume using MRI in adolescents with MDD and age- and sex-matched healthy controls. Studies of 
younger patients with MDD near illness onset are critical in our efforts to delineate the pertinent neurobiological substrates of the disorder and to minimize the confounds of course of illness and treatment intervention.

\section{Methods \\ Subjects}

Seventeen subjects with MDD aged 13 to 18 years ( 8 males and 9 females) and 17 healthy controls matched pairwise for age and sex were recruited. The age of onset of the first clinical presentation in the patients with MDD was $14.06 \pm 1.98$ years (mean \pm SD). Duration of illness in the MDD subjects was $2.89 \pm 1.71$ years. All case-control pairs were matched within 12 months of each other.

Patients were recruited after being referred to the Izaak Walton Killam (IWK) Health Center's department of Psychiatry. Controls were garnered through advertisement. Both patients and controls were paid a small honorarium for their participation in the study. The Schedule for Affective Disorders and Schizophrenia for School-Age Children-Present Lifetime version (K-SADS-PL [19]) was used to establish diagnosis. Exclusion criteria for participation in this study were a history of neurological illness, serious medical illness, claustrophobia, age greater than 18 years, or the presence of a ferrous implant or pacemaker. Depression symptom severity was assessed using the Childhood Depression Rating Scale [20] (CDRS; score = $65.35 \pm 13.87$ [mean \pm SD]). All depressed subjects had a CDRS score above 42 , indicative of significant dysfunction. Nine MDD subjects had a family history of a mood disorder. Two subjects had a comorbid diagnosis of substance abuse and one subject had comorbid diagnosis of oppositional defiant disorder. Three MDD subjects had recently started medication (sertraline, methylphenidate and zopiclone). The remainder of the MDD subjects was treatment naïve $(n=14)$. Controls did not have any psychiatric illness. Controls were also screened for depression with the CDRS (score $=40.35 \pm 13.69$ [mean \pm SD]). Written informed consent was obtained prior to initiating the study in compliance with the IWK Research Ethics Board.

\section{MRI data acquisition}

The MRI studies were conducted with a 1.5 Tesla Siemens Magnetom Vision magnetic resonance system (Germany). A sagittal scout series was acquired to test image quality. A three-dimensional fast low angle shot (FLASH) sequence was used to acquire data from 124 1.5-mm thick contiguous coronal slices through the entire brain (echo time $=5$ ms, repetition time $=25 \mathrm{~ms}$, acquisition matrix $=256 \times$ 256 pixels, field of view $=24 \mathrm{~cm}$ and flip angle $=40^{\circ}$ ). Positioning was done in a standardized manner in order to ensure consistency of acquisitions. Images were exported to a computer workstation (Macintosh G4, Apple Computer, Cupertino, California).

\section{Image analysis}

Anatomical boundaries were determined from neuroanatomical atlases [21,22]. Anatomical data were analyzed using National Institutes of Health Imaging software (NIHImage 1.62), a semi-automated segmentation algorithm for obtaining reliable quantitative neuroanatomical measurements [23]. Mathematical cutoffs for gray matterwhite matter-cerebral spinal fluid divisions were determined with histograms of signal intensity. A point counting stereological approach based on the Cavalieri theorem of systematic sampling has validated this method, and both methods have documented validity and sensitivity with high correlations $(r=0.96)$ [23].

Left and right hippocampal volumes were measured separately. A manual tracing technique was used to delineate the hippocampus (see Figure 1). Although primarily measured in the coronal plane, all three views (coronal, sagittal and axial) were referenced in order to more accurately segment the hippocampus from the surrounding tissue. Anatomical boundaries were based on the following criteria. For the anterior border, separating the hippocampus from the amygdala was paramount. The appearance of the mammiliary bodies was used a landmark to demarcate roughly where the amygdala starts to appear as one moves to the anterior of the brain from the posterior. As slices move anteriorly, amygdala gray matter begins to extend superior to the hippocampus. With good resolution, the lateral ventricle can be seen between the hippocampus and amygdala. Sagittal views aided in this demarcation. The posterior border was demarcated by the clearest appearance of the fornix. The lateral border was defined by the temporal horn of the lateral ventricle and / or the white matter adjacent to the hippocampal gray matter. The inferior border was demarcated by the white matter of the parahippocampal gyrus. Summed areas and slice thickness were used to calculate volume (right: $20.32 \pm$ 2.85 slices; left: $20.15 \pm 2.89$ slices [mean \pm SD]). Hippocampal length was calculated by multiplying the number of slices by the slice thickness.

All measurements were done in a blinded manner by a trained rater (FPM) in a single batch. Interrater reliabilities were high (0.98) as were intrarater reliabilities (0.99) for hippocampal measures. Finished measurements were transformed into axial and sagittal slices in order to determine if adequate hippocampal coverage was achieved. By using all three dimensions of the data set, we feel that we can accurately measure hippocampal volume by taking advantage of all three views.

\section{Data analysis}

An analysis of covariance (ANCOVA) with age, sex, and intracranial volume as covariates was used to compare hippocampal volumes. Unpaired t-tests were used to 
A.

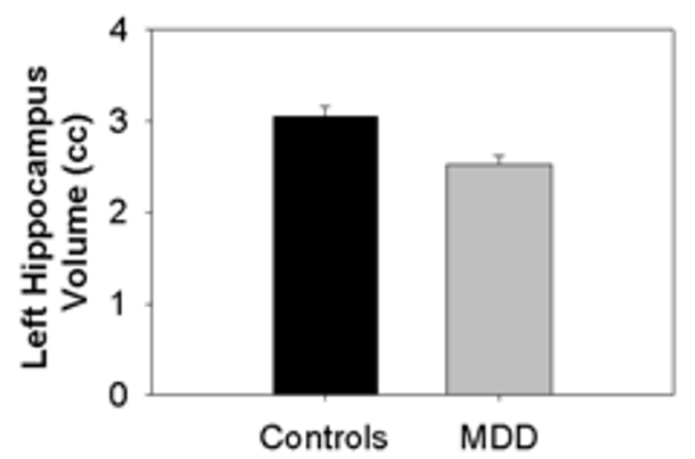

B.

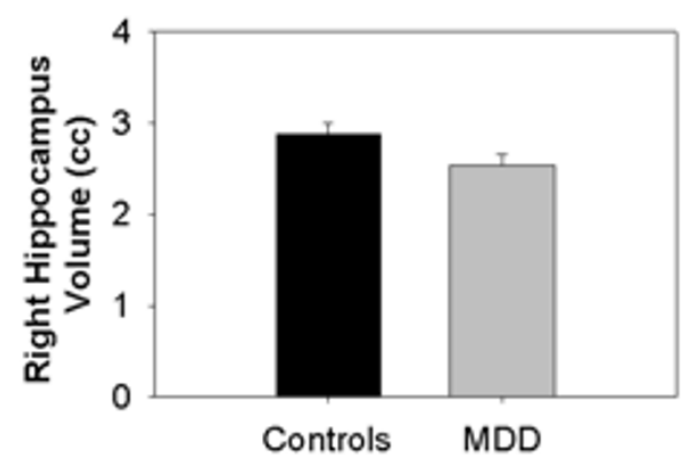

Figure I

Sample MRI scans showing the manual tracing technique of the hippocampus. (a) Full coronal image of the brain. (b) Sagittal view of the length of the hippocampal measurement. (c) A section of the image at $2 \times$ magnification showing a close-up of the hippocampus in that slice. (d) The hippocampus traced (white outline).

examine differences in demographic variables and depressive symptoms. Clinical and developmental correlations were conducted using Pearson correlations. Two-tailed test significance was used throughout, with statistical significance defined as $\mathrm{P}<0.05$. All analyses were conducted using SPSS software (SPSS Inc, Chicago, Ill).

\section{Results}

The ANCOVA revealed a significant difference between MDD and control subjects $(\mathrm{F}=8.66, \mathrm{df}=1,29, \mathrm{P}=0.006)$. This was more strongly localized to the left hippocampus (controls: $3.05 \pm 0.11 \mathrm{~cm}^{3}$; MDD: $2.53 \pm 0.09 \mathrm{~cm}^{3}$ [mean $\pm \mathrm{SE}$; $\mathrm{P}=0.001$ ) than the right hippocampus (controls: $2.88 \pm 0.11 \mathrm{~cm}^{3} ;$ MDD: $2.54 \pm 0.12 \mathrm{~cm}^{3}[$ mean $\pm \mathrm{SE}] ; \mathrm{P}=$ 0.047) (see Figure 2). Left hippocampal length was also smaller in adolescent MDD subjects compared to case matched controls (mean \pm SE controls: $3.14 \pm 0.09 \mathrm{~cm}$; MDD: $2.70 \pm 0.09 \mathrm{~cm}[$ mean $\pm \mathrm{SE}] ; \mathrm{t}=4.55, \mathrm{df}=16, \mathrm{P}<$ $0.001)$. Upon consideration of only the pairs using treatment naïve MDD subjects (14 pairs), the findings remained, with smaller left hippocampal volumes being noted in the treatment naïve depressed adolescents (controls: $3.01 \pm 0.13 \mathrm{~cm}^{3}$; MDD: $2.48 \pm 0.13 \mathrm{~cm}^{3}[$ mean \pm SE]; $\mathrm{F}=10.83, \mathrm{df}=1,26, \mathrm{P}=0.003$ ). Age did not correlate with any measure of the hippocampus in either group.

As expected, MDD subjects were significantly more depressed than controls $(\mathrm{t}=5.29, \mathrm{df}=22, \mathrm{P}<0.001)$. CDRS scores did not correlate with hippocampal volumes in the depressed subjects or the controls. In the depressed subjects, age of onset was negatively correlated with left hippocampal volumes $(\mathrm{r}=-0.59, \mathrm{P}=0.03)$. However, duration of illness was positively correlated with left hippocampal volume $(\mathrm{r}=0.57, \mathrm{P}=0.04)$.

Comparable ages were observed in male $(16.66 \pm 2.06$ years [mean \pm SD] $)$ and female patients with MDD (16.67 \pm 1.74 years $[$ mean $\pm S D] ; t=0.02, d f=15, P=0.98$ ) indicating that the age ranges in the two sexes were similar. Age at onset of illness did not differ between male and female patients (male: $166.17 \pm 20.15$ months; female: $170.63 \pm 27.27$ months [mean $\pm \mathrm{SD}$ ]; $\mathrm{t}=0.34, \mathrm{df}=12, \mathrm{p}$ $=0.74$ ). The smaller volume shown in the left hippocampus was more prominent in males (controls: $3.38 \pm 0.44$ $\mathrm{cm}^{3}$; MDD: $2.65 \pm 0.38 \mathrm{~cm}^{3}$ [mean $\left.\pm \mathrm{SD}\right] ; \mathrm{t}=3.51, \mathrm{df}=14$, $\mathrm{P}=0.004$ ) than females (controls: $2.76 \pm 0.21 \mathrm{~cm}^{3}$; MDD: $2.42 \pm 0.37 \mathrm{~cm}^{3}[$ mean $\left.\pm S D] ; t=2.39, d f=16, P=0.03\right)$.

\section{Discussion}

The principal finding of this study is a smaller left hippocampal volume (by $17 \%$ ) in early onset adolescent depression as compared to age- and sex-matched healthy controls. In past studies that reported positive findings regarding decreased hippocampal volumes in depressed patients, a decrease of similar magnitude was noted (8 $19 \%)[4,5,9,10]$. Similar to another study, the smaller hippocampal volume was more prominent in males than females [11]. Akin to the trend noted by MacMillan and colleagues [24], the difference was also more substantial on the left than the right. Hippocampal size did not correlate with age in either group. However, hippocampal size was correlated negatively with age of onset in the depressed subjects. This is consistent with Steffens and others' [8] finding of smaller hippocampal size associated 
A.

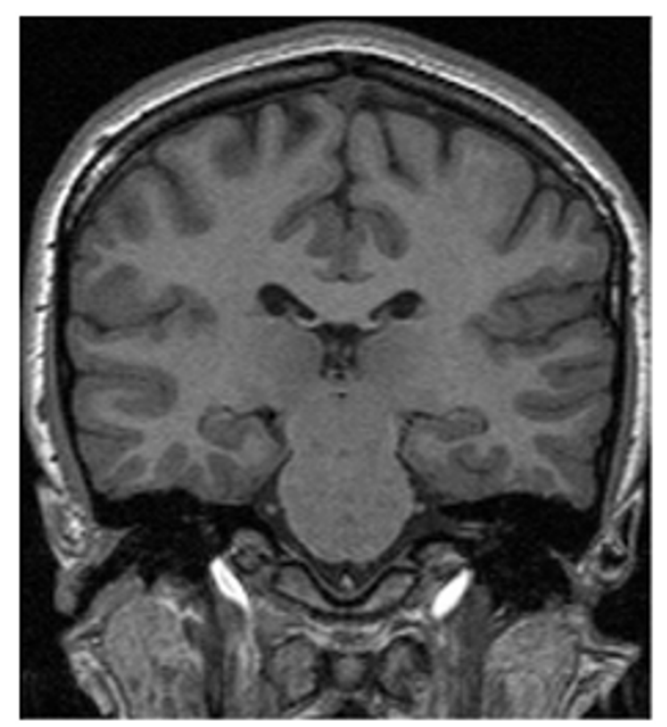

B.

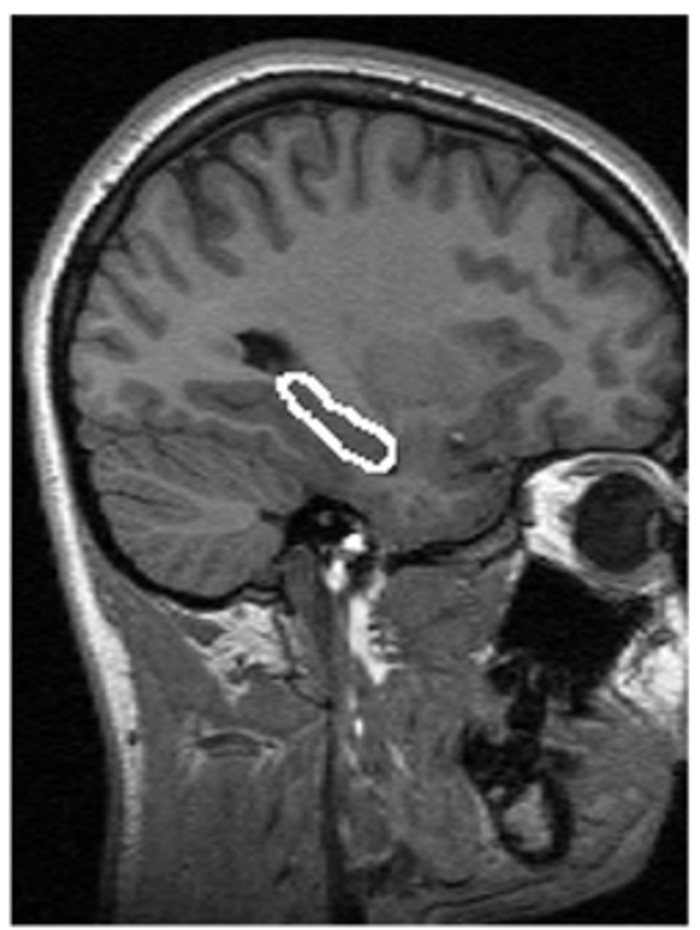

c.

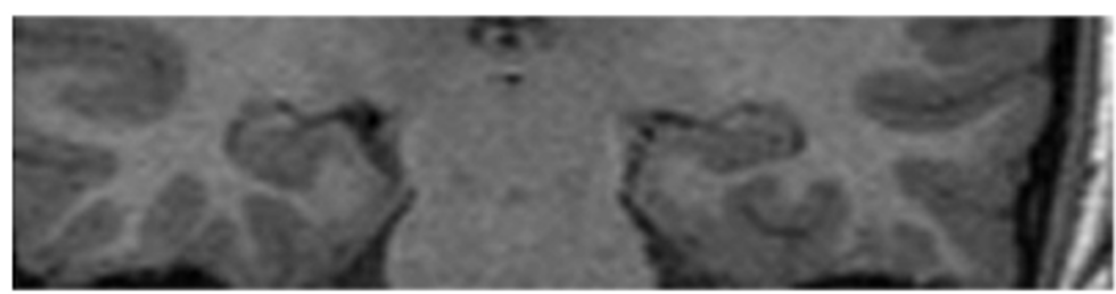

D.

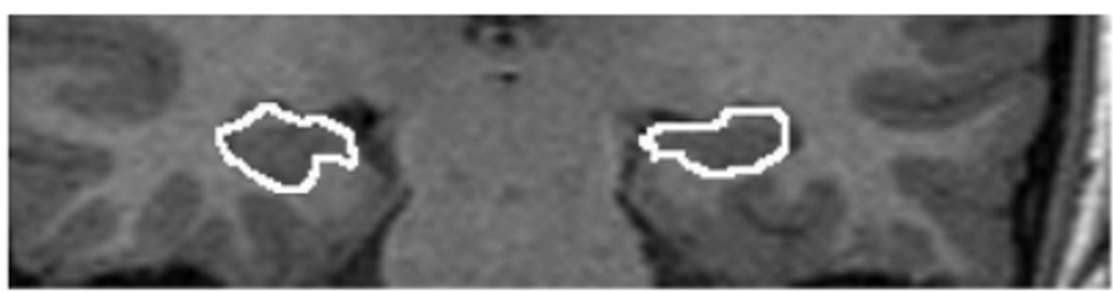

Figure 2

Graphs of hippocampal results. (a) Left hippocampus in controls and depressed youth and (b) right hippocampus in controls and depressed youth. 
with older age of onset. Of special interest is that we noted a positive correlation with duration of illness and hippocampal size. This may explain why younger adult studies of depression (as opposed to middle aged and elderly samples) have not shown a decrease in hippocampal size [25], as the difference may be lost during early adulthood. However, this should be considered speculative and the correlation should be replicated. As these patients were all early onset cases, we cannot speculate about the effects of number of episodes on hippocampal volume.

It is a commonly held hypothesis that cell loss related to depression in the hippocampus involves glucocorticoids. Glucocorticoid hypersecretion can lead to cell death in the hippocampus and may be responsible for the cell loss noted in this region in a number of neuropsychiatric disorders [26]. Hyperactivity of the hypothalamic-pituitaryadrenal (HPA) axis is a relatively consistent finding in adults with MDD, with hypercortisolemia being prominent [27]. This is state-dependent and tends to resolve with recovery. Hence, the relationship between the number of days depressed and atrophy in the hippocampus noted by Sheline et al. [5] is logical, as excessive glucocorticoids can lead to increased cell death [26]. In adolescents with depression, the evidence of cortisol abnormalities is much less compelling. One study failed to note any differences in the summary cortisol measures [28], while two studies noted an increase in cortisol after sleep onset in depressed adolescents [29,30]. After sleep onset, cortisol is usually quiescent. It has been hypothesized that it reflects more of a variation in the diurnal variation of cortisol than a robust increase in overall cortisol activity [29,30]. Mineralcorticoid (MR) receptors appear to be operative at low cortisol concentrations and may offer tonic inhibition to the HPA axis during the nadir of the circadian rhythm [31,32]. As the diurnal activity of the HPA axis is disrupted in MDD youth, particularly when cortisol activity is at its lowest [29,30], it may be indicative of altered MR function, with MRs being found in the amygdala and hippocampus. Classic cortisol hypersecretion is thought to be rare in depressed children and adolescents [33]. This is also consistent with our lack of a negative correlation between duration of illness and left hippocampal volume in depression. However, the reasons behind the positive correlation are unclear and require replication.

As positive correlations have previously been noted between hippocampal volume and anxiety in depressed subjects and controls [24,25], the fact that we did not control for this may represent a limitation of this study. No subject had a comorbid anxiety disorder, however, and unlike the depressed subjects with anxious symptoms used in the study by Rusch et al. [25], our sample demonstrated differences in volume when comparing diagnostic groups. It is also worth noting that Vythilingam and col- leagues [34] did not find any differences in hippocampal volume in panic disorder, and hence anxiety may not have as profound an effect on hippocampal volume as one would assume.

To our knowledge, this is the first published report regarding hippocampal volume in youth with early onset depression compared to healthy controls. These conclusions should be considered preliminary, considering the small sample sizes used. Future directions include the examination of high-risk for depression subjects, larger sample sizes and longitudinal studies of illness course. The use of convergent measures such as tests of working memory along with the volumetric data would also be of value. Also, the evaluation of related limbic structures, such as the amygdala, using MRI is of keen interest.

\section{Conclusions}

We have noted smaller left hippocampal volumes in depressed adolescents compared to healthy age- and sexmatched controls. This decrease was negatively correlated with age of onset, indicating a smaller hippocampus in those experiencing a later age of onset. Left hippocampal volumes were positively correlated with duration of illness and may reflect a differential developmental course incurred by the disorder or an attempt at recovery by the body.

\section{Competing Interests}

None declared.

\section{Author's Contributions}

FM contributed the experimental design, acquisition, analysis and interpretation. VK contributed to the experimental design, patient recruitment and assessment. Both authors contributed to the manuscript.

\section{Acknowledgements}

The authors wish to thank Drs Kazue Semba and John Connolly for helpful comments on the manuscript. The authors would also like to thank the Nova Scotia Health Research Foundation and the Theodore and Vada Stanley Foundation for their support.

\section{References}

I. Lewinsohn PM, Duncan EM, Stanton AK, Hautzinger M: Age at first onset for nonbipolar depression. J Abnorm Psychol 1986, 95:378-383.

2. Soares JC, Mann J]: The anatomy of mood disorders-review of structural neuroimaging studies. Biol Psychiatry 1997, 41:86-106.

3. Krishnan KR, Doraiswamy PM, Figiel GS, Husain MM, Shah SA, Na C, Boyko OB, McDonald WM, Nemeroff CB, Ellinwood EH: Hippocampal abnormalities in depression. J Neuropsychiatry Clin Neurosci |991, 3:387-391.

4. Sheline YI, Wang PW, Gado MH, Csernansky JG, Vannier MW: Hippocampal atrophy in recurrent major depression. Proc Natl Acad Sci U S A 1996, 93:3908-3913.

5. Sheline YI, Sanghavi M, Mintun MA, Gado MH: Depression duration but not age predicts hippocampal volume loss in medically healthy women with recurrent major depression. J Neurosci 1999, 19:5034-5043. 
6. Shah PJ, Ebmeier KP, Glabus MF, Goodwin GM: Cortical grey matter reductions associated with treatment-resistant chronic unipolar depression. Controlled magnetic resonance imaging study. Br J Psychiatry 1998, I 72:527-532.

7. Bremner JD, Narayan M, Anderson ER, Staib LH, Miller HL, Charney DS: Hippocampal volume reduction in major depression. Am J Psychiatry 2000, I 57: I I5-8.

8. Steffens DC, Byrum CE, McQuoid DR, Greenberg DL, Payne ME, Blitchington TF, MacFall JR, Krishnan KR: Hippocampal volume in geriatric depression. Biol Psychiatry 2000, 48:30I-309.

9. Mervaala E, Fohr J, Kononen M, Valkonen-Korhonen M, Vainio P, Partanen K, Partanen J, Tiihonen J, Viinamaki H, Karjalainen AK, Lehtonen J: Quantitative MRI of the hippocampus and amygdala in severe depression. Psychol Med 2000, 30: I 17-125.

10. Vythilingam M, Heim C, Newport J, Miller AH, Anderson E, Bronen R, Brummer M, Staib L, Vermetten E, Charney DS, Nemeroff CB, Bremner JD: Childhood trauma associated with smaller hippocampal volume in women with major depression. $\mathrm{Am} J$ Psychiatry 2002, 159:2072-2080.

II. Frodl T, Meisenzahl E, Zetzsche T, Bottlender R, Born C, Groll C, Jager M, Leinsinger G, Hahn K, Moller HJ: Enlargement of the amygdala in patients with a first episode of major depression. Biol Psychiatry 2002, 5 I:708-7|4.

12. Axelson DA, Doraiswamy PM, McDonald WM, Boyko OB, Tupler LA, Patterson LJ, Nemeroff CB, Ellinwood EH, Krishnan KR: Hypercortisolemia and hippocampal changes in depression. Psychiatry Res 1993, 47:163-173.

13. Coffey CE, Wilkinson WE, Weiner RD, Parashos IA, Djang WT, Webb MC, Figiel GS, Spritzer CE: Quantitative cerebral anatomy in depression. A controlled magnetic resonance imaging study. Arch Gen Psychiatry 1993, 50:7-16.

14. Ashtari M, Greenwald BS, Kramer-Ginsberg E, Hu J, Wu H, Patel M, Aupperle $P$, Pollack S: Hippocampal/amygdala volumes in geriatric depression. Psychol Med 1999, 29:629-638.

15. Pantel J, Schroder J, Essig M, Popp D, Dech H, Knopp MV, Schad LR, Eysenbach K, Backenstrass M, Friedlinger M: Quantitative magnetic resonance imaging in geriatric depression and primary degenerative dementia. J Affect Disord 1997, 42:69-83.

16. Vakili K, Pillay SS, Lafer B, Fava M, Renshaw PF, Bonello-Cintron CM, Yurgelun-Todd DA: Hippocampal volume in primary unipolar major depression: a magnetic resonance imaging study. Biol Psychiatry 2000, 47: 1087-1090.

17. Sheline YI: 3D MRI studies of neuroanatomic changes in unipolar major depression: the role of stress and medical comorbidity. Biol Psychiatry 2000, 48:79I-800.

18. Hendren RL, De Backer I, Pandina GJ: Review of neuroimaging studies of child and adolescent psychiatric disorders from the past 10 years. I Am Acad Child Adolesc Psychiatry 2000 39:8I5-828.

19. Kaufman J, Birmaher B, Brent D, Rao U, Flynn C, Moreci P, Williamson D, Ryan N: Schedule for Affective Disorders and Schizophrenia for School-Age Children-Present and Lifetime Version (K-SADS-PL): initial reliability and validity data. J Am Acad Child Adolesc Psychiatry 1997, 36:980-988.

20. Poznanski E, Mokros HB, Grossman J, Freeman LN: Diagnostic criteria in childhood depression. $\mathrm{Am} /$ Psychiatry 1985 | 42: I |68-1 I 73 .

21. Daniels DL, Haughton VM, Naidich TP: Cranial and spinal magnetic resonance imaging: An atlas and guide New York: Raven Press; 1987.

22. Talairach J, Tournoux P: Co-planar stereotaxic atlas of the human brain New York: Thieme-Stratton Inc.; 1988

23. Keshavan MS, Anderson S, Beckwith C, Nash K, Pettegrew JW, Krishnan KR: A comparison of stereology and segmentation techniques for volumetric measurements of lateral ventricles in magnetic resonance imaging. Psychiatry Res 1995, 6I:53-60.

24. MacMillan S, Szeszko PR, Moore GJ, Madden R, Lorch E, Ivey J, Banerjee SP, Rosenberg DR: Increased amygdala: hippocampal volume ratios associated with severity of anxiety in pediatric major depression. J Child Adolesc Psychopharmacol 2003, 13:65-73.

25. Rusch BD, Abercrombie HC, Oakes TR, Schaefer SM, Davidson RJ: Hippocampal morphometry in depressed patients and control subjects: relations to anxiety symptoms. Biol Psychiatry 200I, 50:960-964

26. Sapolsky RM: Glucocorticoids and hippocampal atrophy in neuropsychiatric disorders. Arch Gen Psychiatry 2000, 57:925-935.
27. Holsboer F, Lauer CJ, Schreiber W, Krieg JC: Altered hypothalamic-pituitary-adrenocortical regulation in healthy subjects at high familial risk for affective disorders. Neuroendocrinology 1995, 62:340-347.

28. Dahl R, Puig-Antich J, Ryan N, Nelson B, Novacenko H, Twomey J, Williamson D, Goetz R, Ambrosini PJ: Cortisol secretion in adolescents with major depressive disorder. Acta Psychiatr Scand 1989, 80:18-26.

29. Kutcher S, Malkin D, Silverberg J, Marton P, Williamson P, Malkin A Szalai J, Katic M: Nocturnal cortisol, thyroid stimulating hormone, and growth hormone secretory profiles in depressed adolescents. I Am Acad Child Adolesc Psychiatry 1991, 30:407-4I4.

30. Dahl RE, Ryan ND, Puig-Antich J, Nguyen NA, al-Shabbout M, Meyer VA, Perel J: 24-hour cortisol measures in adolescents with major depression: a controlled study. Biol Psychiatry |99|, 30:25-36.

31. De Kloet ER, Rosenfeld P, Van Eekelen JA, Sutanto W, Levine S: Stress, glucocorticoids and development. Prog Brain Res 1988, 73:101-120

32. McEwen BS: Stress and hippocampus. An update on current knowledge. Presse Med 199|, 20:|80|-|806.

33. Kaufman J, Ryan D: The neurobiology of child and adolescent mood disorders. In: Neurobiology of mental illness Edited by: Charney DS, Nestler EJ, Bunney BS. New York: Oxford; 1999:810-822.

34. Vythilingam M, Anderson ER, Goddard A, Woods SW, Staib LH, Charney DS, Bremner JD: Temporal lobe volume in panic disorder - a quantitative magnetic resonance imaging study. Psychiatry Res 2000, 99:75-82.

\section{Pre-publication history}

The pre-publication history for this paper can be accessed here:

http://www.biomedcentral.com/1741-7015/2/2/prepub
Publish with Bio Med Central and every scientist can read your work free of charge

"BioMed Central will be the most significant development for disseminating the results of biomedical research in our lifetime. "

Sir Paul Nurse, Cancer Research UK

Your research papers will be:

- available free of charge to the entire biomedical community

- peer reviewed and published immediately upon acceptance

- cited in PubMed and archived on PubMed Central

- yours - you keep the copyright
BioMedcentral 